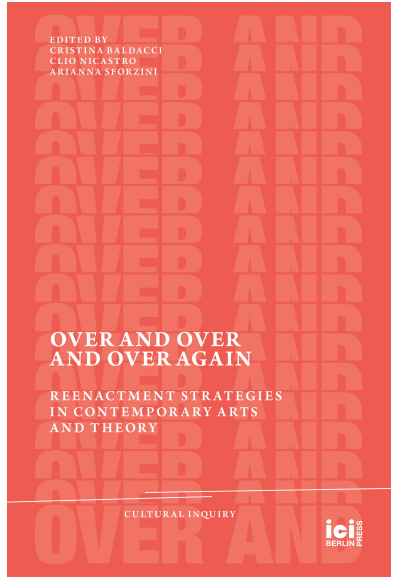

Over and Over and Over Again: Reenactment Strategies in Contemporary Arts and Theory, ed. by Cristina Baldacci, Clio Nicastro, and Arianna Sforzini, Cultural Inquiry, 21 (Berlin: ICI Berlin Press, 2022), pp. 205-18

\author{
VERA SOFIA MOTA \\ FRANSIEN VAN DER PUTT
}

\section{Unfold Nan Hoover}

\section{On the Importance of Actively Encouraging a Variable Understanding of Artworks for the Sake of their Preservation and Mediation}

\section{CITE AS:}

Vera Sofia Mota and Fransien van der Putt, 'Unfold Nan Hoover: On the Importance of Actively Encouraging a Variable Understanding of Artworks for the Sake of their Preservation and $\mathrm{Me}$ diation', in Over and Over and Over Again: Reenactment Strategies in Contemporary Arts and Theory, ed. by Cristina Baldacci, Clio Nicastro, and Arianna Sforzini, Cultural Inquiry, 21 (Berlin: ICI Berlin Press, 2022), pp. 205-18 <https://doi.org/10.37050/ci$2121>$

\section{RIGHTS STATEMENT:}

\author{
(C) by the author(s) \\ Except for images or otherwise noted, this publication is licensed \\ under a Creative Commons Attribution-ShareAlike 4.0 Inter- \\ national License.
}

ABSTRACT: To support the practice of preservation and mediation of video works in the LIMA Collection (Amsterdam), the authors explore the possibilities of reinterpretation as a rather common practice in the performing arts. As a choreographer and a dramaturge, they establish a correlation between reinterpretation and dramaturgy - as a way to deal with non-objective or transitory aspects of the works and describe their method in relation to the video and performance artist Nan Hoover.

KEYWORDS: dramaturgy; preservation; reinterpretation; reenactment; mediation; choreography; non-objective; Nan Hoover; LIMA; video art; performance art; archive 


\section{Unfold Nan Hoover}

On the Importance of Actively Encouraging a Variable Understanding of Artworks for the Sake of their Preservation and Mediation

VERA SOFIA MOTA AND FRANSIEN VAN DER PUTT

\section{INTRODUCTION}

The variable, ephemeral aspects of a work of art can pose problems for those who want to preserve it. On the one hand, questions need to be answered, including whether the desired preservation relates to issues of presentation, heritage, or trade, and if the work in its current state can be identified and justified as 'the' work. On the other hand, there is artistic work that speculates on variability. For instance, new media and digital art tend to travel platforms or manifest themselves by generating new form and content in the course of, or 'as', their existence. Theatre has a very different attitude towards preservation and lacks the obsession with an original object and thus also the consequent sense of loss so common to visual art.

In the performing arts, if preservation is considered at all, professionals often use audio-visual $(\mathrm{AV})$ recordings to document a practice or a performance. Formal compositions are instead kept in scores, ranging from personal notes to shared scoring systems to official music and dance notations or textbooks. Instructions or ideas about how and 
why to perform a certain work are often preserved in personal archives, which are rarely published.

In music it is common to publish audio recordings and, although it is radically less common, in opera, dance, and theatre $\mathrm{AV}$ recordings are sometimes published. In the performing arts the work is also preserved by a (cross-generational) transfer through practice and routine through trainings, workshops, and rehearsals. A recent trend in dance adds to this tradition by shifting interest from AV recordings documenting individual works to publications that reflect more broadly on artistic method and aesthetics - this is the case with choreographers such as William Forsythe, Boris Charmatz, Emio Greco|PC, Jonathan Burrows, Meg Stuart, and Anne Teresa de Keersmaeker. ${ }^{1}$

One could say that in theatre the work 'itself' or 'as such' is a matter of interpretation and reinterpretation. When created, performed, performed again, or restaged, even the original authors and performers have to make new decisions each time. This is not only due to the variability of conditions and contexts but also because the work itself develops in the course of its coming into being or its existence. The practice of creating and performing 'it' extends into the history of particular reenactions by original authors and all those who have been reinterpreting this 'it' as repertoire.

One might conclude that in the performing arts, instability and variability are foundational aspects to a trade in which an original work can only exist as a result of a process of numerous forms of interpretation and transfer. Whether a work is totally set on agreements between people or has a certain number of formal features to be repeated via scores, notations, or captures both in AV and in the current digitally enhanced $3 \mathrm{D}$ capturing, it always remains a matter of interpretation, or — as the prefix 're-' emphasizes - a continued process of translation into substantiation.

1 See: Boris Charmatz and Isabelle Launay, Entretenir: A propos d'une danse contemporaine (Dijon: Les presses du réel, 2003); William Forsythe, Improvisation Technology: A Tool for the Analytical Dance Eye (Ostfildern: Hatje Cantz, 1999); Capturing Intention: Documentation, Analysis and Notation Research Based on the Work of Dance Company Emio Greco|PC, ed. by Scott deLahunta (Amsterdam: AHK-Amsterdam University of the Arts, 2007); Are We Here Yet, ed. by Jeroen Peeters and Meg Stuart (Dijon: Les presses du réel, 2010); Jonathan Burrows, A Choreographer's Handbook (London: Routledge, 2010); Anne Teresa De Keersmaeker and Bojana Cvejić, A Choreographer's Score: Fase, Rosas danst Rosas, Elena's Aria, Bartók (Brussels: Mercatorfonds-Rosas, 2012). 
Variability also has consequences for notions of ownership and authorship. The original work resides in a mix of prescribed and reenacted aesthetics. The work, as understood by its authors and performers, is depending on an ongoing choice-making process and on notions of improvisation. Any degree of improvisation gives the performers co-auctorial power, or at least the responsibility that goes with it. Formal instructions, individual processes of actualization, and conventions and traditions in production and presentation accumulate in a process shared between many different practitioners, generations, and disciplines.

Firstly, original authors within the different performing art traditions choose what part of the work needs to be prescribed and what part is left to the discretion of the people responsible for performing it. ${ }^{2}$ Secondly, many theatre works become part of a repertoire. Repertoire is available to a multitude of practitioners, not only due to the publication of recordings, scores, notations, or documentations but also because of a widespread engagement with the work through popular culture and amateur practice.

Needless to say, convention is what keeps the performing arts together, as much as its artistic development or 'progress' depends on breaking the rules of that same convention. This is the exact point where dramaturgy comes in as a way to understand and investigate the process of designing the rules and the functionality for the usage of materials in a specific work that has to be presented in a specific way.

In the performing arts, notions of authenticity, finality, and ownership are being challenged. These challenges typically occur through dramaturgy, because in the course of creating a work - either staged or performed live - dramaturgical features implicitly specify the ways and the reasons through which matters and actions are related, not only with respect to each other but also with respect to other works, conventions of art, and to society and the historical world at large. It is often the specific form of variability through which a work creates an

2 In general, artists that stage and design are also considered authors. Performers tend to be excluded from this, although for instance in Belgium and the Netherlands since the 1960s, theatre groups of all kinds (text, object, visual, music, dance, and mime) have developed ways of working in which authorship is shared, and auctorial and performative roles are combined or vary per project. 
alignment with - as much as it breaks away from - common systems of signification and regimes of perception, that mark the work's specific form.

\section{UNFOLD NAN HOOVER}

Since 2015, we have been researching the oeuvre of Nan Hoover (born in New York in 1931, died 2008 in Berlin), a pioneer in performance and video art and among the most prominent artists in the LIMA Collection. ${ }^{3}$ As a choreographer (Mota) and a dramaturge (van der Putt), who have been collaborating since 2011, we were invited by LIMA to prepare a new work, which could be based on either one or several of Hoover's works. The context of the commission was the research project, UNFOLD: Mediation by Reinterpretation, organized by Gaby Wijers and Lara Garcia Diaz in 2016-17. The project undertook a comprehensive exploration of reinterpretation as a crossdisciplinary archival strategy from different levels of practice, positions in the field, and disciplinary backgrounds, beyond the tradition of object-based preservation and literal reenactment widespread in the institutionalized visual art world.

Keeping a balance between practical and theoretical references, the project tried to both affiliate and cross notions and practices of scholars, institutional presenters, and preservationists with those of independent artists and researchers from different fields working with time based arts: i.e., video, film, installation, sound art, performance, and performing arts such as music, theatre, and dance.

\section{VARIABILITY}

In her contribution to the project, LIMA's director Gaby Wijers refers to the Variable Media Network, a Canadian initiative from the late 1990s, which proposed a flexible approach to the preservation of a

3 LIMA is a new media and digital art platform based in Amsterdam. Initiated by former staff members of the Dutch Media Art Institute (NIMk) when the latter lost its funding in 2012, the platform takes care of and distributes an impressive collection, which is kept up to date with new acquisitions but also clearly links back to the artist initiatives and organizations upon whose collective practice, artistic invention, knowhow, and activist mindset NIMk was built: Montevideo and Time Based Arts. 
range of creative practices, challenging traditional notions of preservation and investing in the notion of variable media. Within this approach, reinterpretation is defined as 'the most radical preservation strategy', as it implies 'reinterpret[ing] the work each time it is recreated. ${ }^{4}$ For the Variable Media Approach Project, reinterpretation is 'a dangerous technique when not warranted by the artist, but it may be the only way to re-create performed, installed, or networked art designed to vary with context. ${ }^{5}$

The variability of visual artworks normally concerns three different aspects: (1) forms of deterioration of the original object; (2) technology that carries (part of) the artwork turning obsolete; and (3) a lack of clarity about the 'rules' according to which the work should function, especially when works are already constructed to change or vary.

Nan Hoover's pieces collected at LIMA are video works. On the one hand, these seem to be rather stable objects, although they have been affected by deterioration and change due to the aging of materials, certain forms of video technology becoming obsolete, and the transfer of the work to digital formats for preservation and (online) mediation.

On the other hand, there are instances of variability that emerge from the collection's policy over the years. For instance, considering the way they are described in LIMA's online catalogue, it is hard to determine the dimensions in which Hoover initially presented her works. The digital files can be projected in any size, but originally Hoover chose a specific form of presentation: a monitor, a screen, or another type of projection tool with a specific projection-size. To change the size of the projection means to alter the work, at least in terms of its spatial and temporal qualities.

Thinking of devices, one could also be tempted to regard the original installation setting of certain works as crucial. How and where

4 UNFOLD: Mediation by Re-interpretation - Annual Project Review Report, March 2016-March 2017, ed. by Gaby Wijers, Lara Garcia Diaz, and Christian Sancto (Amsterdam: LIMA, 2017), p. 15 <https://www.li-ma.nl/lima/sites/default/files/ Unfold_verslag_excl.pdf> [accessed 19 July 2019].

5 See the 'Variable Media Glossary', in The Variable Media Approach: Permanence through Change, ed. by Alain Depocas, Jon Ippolito, and Caitlin Jones (New York: Guggenheim Museum Publications, 2003), pp. 123-37 (p. 128) < https://www.variablemedia.net/ e/preserving/html/var_pub_index.html> [accessed 10 March 2021]. 
devices were installed could be considered an important part of the 'original' work. None of this is mentioned in LIMA's catalogue. Does this mean that users of the archive are free to project the work in any size?

For whatever reason, the builders of the archive have added a new dimension to the work of Hoover, since information concerning the original equipment and set-up that she used for her exhibitions, installations, and events is left open.

One should not forget that Hoover herself opted for various systems when presenting a specific work during her lifetime. Not only was she working with the new medium of video, which meant that the device or format was changing constantly, but she also might have been changing the size of her monitor or projection because of new artistic choices, as a matter of artistic strategy, or as a form of improvisation during the installation of her work in each different display.

How do we present Hoover's work now, if she is no longer there to authorize its installation? How do we look at it now, even just in terms of size? Did Hoover care? Should LIMA care and everyone else approaching her work?

\section{INTERMEDIA}

Hoover's entire oeuvre consists of works in many different media. She produced paintings and drawings, videos, films and photographs, and performances and performative installations. In addition to prestigious institutions like Documenta in Kassel or the Museum of Modern Art in New York, Hoover also exhibited in small galleries or squats.

When looking into the personal archive of Hoover - as both her former assistant and artist Sandro Đukić and art historian Dawn Leach have done to organize her artistic inheritance and produce a catalogue raisonné on behalf of the Nan Hoover Foundation - it becomes clear that certain works exist in different versions, or are linked to a certain line of work. The many studies and sketches that are part of her inheritance attest to this.

The diversity of media and settings she worked with combines with a methodical approach that is overwhelmingly consistent. You will immediately recognize a Hoover when you see one. In lectures, 
writings and interviews, Hoover has commented on specific works and on her method. Critics and scholars have written about it. This kind of information often conjures the work as if it were present. But once the artist is no longer there, it becomes rather difficult to decide how to preserve, present, install, or remediate it in new settings or under new conditions - especially since, in her work, Hoover focused on the materiality of the medium, while questioning it at the same time. Her work is never just representational; it often alludes to issues concerning video, as well as painting, theatre, photography, and the specificity of each medium.

This not only renders the reinstalling, rehanging, or restaging of the work complex, but it also demands a certain responsibility from the archivists - that is, the curators of her archive - in the way they author or authorize her work after her. For instance, during the 2015 retrospective of Hoover's work at the Akademie-Galerie - Die Neue Sammlung in Düsseldorf, Đukić and Wijers decided that some of Hoover's works, which were originally presented on monitors, could be presented with beamers and be projected onto a wall in a size that was remarkably bigger than the average monitor used originally. Although the composition of the work does not really change, the material presence and the temporal experience of its pace changes considerably.

\section{TO BRING ONE'S OWN BODY INTO PLAY}

Often, if not almost always, Hoover included (parts of) herself in the video works she created. The complex relations she set up through playing with her own body in relation to perspective, proportion, pace and space, different sources of light, over- and underexposure, and overlapping shadows covering and uncovering the set-up, emphasize the materiality of the medium in relation to its representational functioning as much as the work obliterates these aspects to achieve a ghostly quality.

In Hoover's work, presence is a complicated and layered issue, often suspended by repetition, extreme forms of slowing down the motion, and disturbing the camera with over- and underexposure, to the point of exhausting the representational. Here, from the surface 
of the canvas to the moving image in video to the time and space of a performative event, conventions of different artistic traditions are being intersected.

In this way, different forms of spectatorship are being addressed. Hoover's experimental approach questions representation not only in relation to the materiality of the medium but also in relation to the corporeality of the spectator, very much speculating on perceptual flaws and hence enchantment. She hardly ever used montage to cut from one perspective to another. Instead, she would use (part of) her body to interfere with several light sources and the depth of field to break the stable perception of the objects in front of the camera.

Hoover's notion of time and space and use of light relate to theatre and dance, as her sense of colour and composition relates to the tradition of painting and sculpture. By putting herself in the work, she turns her sober videos and installations into a rather wild theatre of gestures: object and subject collapse, method and machine become protagonist, the abstract and the concrete compete, and a minimalist staging of different materials and devices causes a strange, ghostly form of interdisciplinary fiction to appear.

\section{REINTERPRETATION AND DRAMATURGY}

We realized that reinterpretation as a strategy has much to do with the postmodern rethinking of modernism, with the postdramatic theatre van der Putt grew up with in the Netherlands, but it actually goes back to a much older discussion about mimesis. As scholar Carlo Ginzburg beautifully described in an essay from 1980 that compares the house doctor, the detective, the hunter, and the fraudulent art dealer Giovanni Morelli, one has to imagine the truth to understand signs as traces or things in time. ${ }^{6}$ Considering the broader definition of reinterpretation, the connection between the performing arts (restaging an opera or a play) and detectives calls for attention. Both have to collect and reread signs in order to stage past events.

To push the process of considering a work that is not yours as if it would or could be, as LIMA's invitation does - that is, to treat

6 Carlo Ginzburg, 'Morelli, Freud and Sherlock Holmes: Clues and Scientific Method', trans. and intro. by Anna Devin, History Workshop, 9 (Spring 1980), pp. 5-36. 
Hoover's work as our material - constantly makes you surf the limit between actualizing things and rewriting them. Dramaturgy matches this interesting moment, as it researches and tries to pinpoint the kind of methodical logic a work demands during its making.

Interpretation traditionally refers to written scores in drama, music, and dance that are being restaged: it means to embody the score through translation, namely, to reinterpret in a different moment or from a different angle, with different instruments, with a different purpose or desire, or with a different dramaturgy.

\section{GHOSTS, ARCHIVES AND EMPOWERMENT}

In theatre we do not work with the idea of origin or of the original work as a stable object. We do work with the ghosts of these terms: for instance, when we speak about a specific authorship or the specifics of a certain work. A score can be an original score, just like a set design. Its author will be considered an original author, but still these artefacts do not give direct access to 'the' original work. It has to be created or manifested time and again, as theatre scholar Maaike Bleeker proposed in her contribution to an event at LIMA as part of the UNFOLD project. ${ }^{7}$ One could even say that each performance is a speculative conversation about the reiteration of not only original ideas, concepts, plans, and scores but also of the latest decisions and deliberations about what has turned out to be the main material and formal base for the process of repeating a staged process - be it an age-old work or a brand new one still to be premiered.

In theatre, thus, the authenticity of an original object is a tricky thing, 'it' being produced in paradoxical, non-linear, or folding ways, which have to transcend a gap through forms of translation. When archiving variable or ephemeral forms of art, it seems imperative not to forcefully stabilize objects, but rather to try and map the different ghosts that constitute their core functioning.

7 Maaike Bleeker, 'Reenactment and the Lifeness of Media', keynote lecture, part of UNFOLD \#3: Reinterpreting the Digital + Workshop Presentation by Joost Rekveld, LIMA, Amsterdam, 1 December 2016 <https://www.li-ma.nl/lima/news/unfold3-reinterpreting-digital-workshop-presentation-joost-rekveld> [accessed 10 March 2021]. 
This reminds us of the archival paradox: you have to allow the archive to have dark spaces and a messy genealogy, to let go of claims or promises for completeness and total transparency, in order for a certain transparency to be met. This means accepting archiving as a form of production, as a process of transfer, mediation, translation, and creation. To be more specific about how you produce in the archive in relation to purposes and political value systems means to do some dramaturgy, for dramaturgical reinterpretation, and archiving practices are closely related.

During another meeting of the UNFOLD project, curator Sarah Cook made an important contribution by pointing out that work redoings, such as reinstallation, reenactment, or reinterpretation, all suggest a certain set of fidelities. ${ }^{8}$ We would like to add that the process of staging a redoing, in whatever form or frame, inevitably leads to forms of infidelity and betrayal - if not just to failure. It is exactly in these limit cases or moments of excess (which, by the way, result from being allowed access) that one can glimpse the original intentions or the former functioning of a work. Here the ghost of an original might appear.

Reinterpretation in relation to the dramaturgical question of (in)fidelity could be a way to map and deal with certain non-objective or transitory aspects of works of art, which are in need of some sort of strategy to survive the archive, the market, etc.

\section{RESPONSIBILITY}

Reinterpretation comes with a certain responsibility. Whatever the nature or grain of the reiteration is, reinterpretation always signifies a certain kind of respect or fidelity for a work or for the body of works you treat. Otherwise, the 're-' simply does not apply anymore.

When pushing the process of reconsidering to the fore or to the limit, a certain criticality is also being produced, not only in relation to the source material but also to one's own practice and work.

8 Sarah Cook, 'Good Artists Copy: Something Better, or At Least Something Different', lecture, 14 September 2016, as part of the workshop 'UNFOLD \#2 Reinterpretation as Creative Act' <https://li-ma.nl/lima/news/unfold-2-reinterpretation-creative-act> [accessed 10 March 2021]. 
Thinking here of Jacques Rancière and his pivotal essay The Emancipated Spectator, one could say that reinterpretation is a form of empowerment or emancipation..$^{9}$ It grants a partial perspective and allows for a playful treatment and critical distance, undermining the patriarchal myth of the original, unique, and autonomous authorship, which so often stultifies both the presentation and the validation of artistic work in an institutional frame.

Considering the differences between the tradition of reenactment and of reinterpretation, it seems that the former is more about reconstructing or reconstituting a forgotten, lost, destroyed, censored, or misrepresented event as object. Many contributions to this volume try to locate and articulate historical gaps and lapses, to compensate for them, or even to restore the lost object to a truer meaning. Reinterpretation, instead, seems a different form of writing - geared towards an actualization of potential in terms of artistic method, means, and material - that permits one to move from one singular perspective to another. As in the case of our project on Hoover's video work, we go beyond the reconstruction or reenactment of the work, as Đukić did with Still Movement: Homage to Nan Hoover (2012). We enter into a dialogue with artistic strategies and choices, while disclosing how the work is inherited, preserved, and mediated.

The original size of Hoover's works is not necessarily one of the most important features, at least not in our relation to them, but questioning the size reveals interesting gaps in how we deal with the artist's intent, artistic heritage, and actual inheritance.

HOW WE WORKED ON THE WORK:

AN EXPLORATION OF METHOD

While approaching Nan Hoover's work, we started intuitively with a close reading of it as it is available at LIMA. ${ }^{10}$ We went from watching the whole body of video works to choosing individual pieces and specific aspects we found striking. From general qualities, like the

9 Jacques Rancière, The Emancipated Spectator, trans. by Gregory Elliott (London: Verso, 2009).

10 To visit the database at LIMA: <http://www.li-ma.nl/site/catalogue/work/list? classes $=$ art $\% 2$ Cdoc\&agents $=$ Nan + Hoover $>$ [accessed 16 December 2019]. 
use of either black and white or colour, the slow pace of bodies in motion, or the repetition, variation, and duration of a work, we moved on to more specific features. We considered the kind of body that is appearing in Hoover's play with the obscuring and uncovering of spatial depth. She often turns her body or body parts into objects or surfaces via the manipulation of perspective, the depth of field, and pace in the videos.

During a residency at Amsterdam University Theatre in June 2016, we explored the videos, streaming them from the online LIMA database and beaming them onto a big screen on the stage of the theatre. We watched the videos for many days, either by ourselves or with invited guests, and discussed our impressions. We imagined how the work was actually created and then presented, how different elements worked out this or that way. We tried to consider what compositional choices were being made, in what context the work was done, what tools were being used, etc. We also imagined how the work would function today and, in contrast, how it had related to another time in art and society.

We then used imitation as a way of reading. Focusing on Hoover's appearing body or body parts, we read her movements, the specific timing and spacing, uses of light and dark, the consequences that the transition to colour has in her work, and the different camera settings she used. Using imitation, we started to mediate the work through new bodies, our bodies, which informed us about the work's limits, possibilities, and impossibilities. Our understanding of the work started to evolve around details, subtleties, hidden questions, or aspects that we would have never noticed by just watching the original videos. Reenacting some aspects of the work meant also becoming aware of the limits of imitating or redoing.

\section{HOW TO CHOOSE?}

The following step, which we have been developing since 2017 in several residencies in Amsterdam, Rotterdam, and Berlin, consisted in composing with varying materials or aspects we had picked from Hoover's work. Departing from the experience of watching, imitating, or redoing, we started to introduce new elements from our own practice. 
Our choice of materials followed the process of getting to know Hoover's work. When watching her videos, we imagined how a live version would work, and which elements would be interesting or challenging to stage. Since we imagine our reinterpretation as a series of performative works, our considerations went towards the performative potential of Hoover's video work.

In the beginning we tended to do the most obvious: to go slowly and to start from variations in the body and movement, following our own expertise. We worked with space, time, the effects of black \& white and colour, adjusting the number of bodies in play, and using the work as a score, projecting a video or just using its sound. At this point, our practice really began to detach from the 'original work'. Instead of relating to a work in its entirety, in terms of movement, light, sound, colour, etc., we chose to work only with one or maybe two elements.

For instance, when working with Hoover's Direction of White Walls (1978), we wondered whether we could repeat the sound and at what volume level we should play it. When introducing a second performer, adding a double into the work, we wondered how to organize the two performers in space. Should they be synchronized or desynchronized? Should we imitate the very typical walking of Hoover, in the sense of copying her posture? What would happen if we changed the pace of the walking and let every performer go at their own very slow pace? What would happen if we just reenacted the spatial trajectory and nothing else?

After these trials, which we used to open up the potential of Hoover's work for our practice and vice versa, we started to compose, finding ways for our practice to produce an interesting insight into her work.

\section{STRATEGIES TO EXPLORE COMPOSITION: EMERGENCE AND MIXING}

To develop strategies and explore ideas for composition, we worked with emergence and mixing as compositional methods. Emergence, a concept often used by Mota in her own work, means that, instead of manipulating materials, one follows a slow process of intensification of the relation with the materials, which allows for compositional choices 
to emerge through the relation with the materials, rather than through preconceived ideas or plans. Following van der Putt's practice we were also mixing works, by putting Hoover's and Mota's work side by side, letting them contaminate and stress what happens in combinations, distortions, accumulation, superposition, variation, etc. At a presentation at Frascati Theatre in Amsterdam during the performance festival 'Come Together' (18-20 January 2017), we put a strobe light from Mota on Hoover's slow walks and used the sound of Direction of White Walls in one of Mota's performative works.

Emergence brings into focus and slows down the compositional process. It allowed us to get to know Hoover's work through adaptation, small changes, and discoveries. Mixing produces quite the opposite process. It allowed us to quickly see differences and similarities when comparing Hoover's and Mota's works; it allowed us to consider both aesthetic harmony and disharmony. Bringing together their works in a rather abrupt or radical way allowed for a fresh look and permitted us to realize how both bodies of work can be perceived.

The many subtle, ghostlike issues that arise from this extremely tangible, experimental practice embedded in artistic deliberations might inform people at LIMA about how to take care of Hoover's work in their collection. Reinterpreting and creating from her work, as well as showing works simultaneously, affects the way we read each of them. While being immersed in the process of (re-)reading, imitating, enacting small variations and recompositions, or composing new ones, the main question for us is: where does her work stop and ours begin? 
Vera Sofia Mota and Fransien van der Putt, 'Unfold Nan Hoover: On the Importance of Actively Encouraging a Variable Understanding of Artworks for the Sake of their Preservation and Mediation', in Over and Over and Over Again: Reenactment Strategies in Contemporary Arts and Theory, ed. by Cristina Baldacci, Clio Nicastro, and Arianna Sforzini, Cultural Inquiry, 21 (Berlin: ICI Berlin Press, 2022), pp. 205-18 <https://doi.org/ $10.37050 /$ ci-21_21>

\section{REFERENCES}

Burrows, Jonathan, A Choreographer's Handbook (London: Routledge, 2010)

Charmatz, Boris, and Isabelle Launay, Entretenir: A propos d'une danse contemporaine (Dijon: Les presses du réel, 2003)

De Keersmaeker, Anne Teresa, and Bojana Cvejić, A Choreographer's Score: Fase, Rosas danst Rosas, Elena's Aria, Bartók (Brussels: Mercatorfonds-Rosas, 2012)

deLahunta, Scott, ed., Capturing Intention: Documentation, Analysis and Notation Research Based on the Work of Dance Company Emio Greco|PC (Amsterdam: AHK-Amsterdam University of the Arts, 2007)

Depocas, Alain, Jon Ippolito, and Caitlin Jones, eds, 'Variable Media Glossary', in The Variable Media Approach: Permanence Through Change (New York: Guggenheim Museum Publications, 2003), pp. 123-37 <https://www.variablemedia.net/e/preserving/html/var pub_index.html $>$ [accessed 12 March 2021]

Forsythe, William, Improvisation Technology: A Tool for the Analytical Dance Eye (Ostfildern: Hatje Cantz, 1999)

Ginzburg, Carlo, 'Morelli, Freud and Sherlock Holmes: Clues and Scientific Method', trans. and intro. by Anna Devin, History Workshop, 9 (Spring 1980), pp. 5-36 <https://doi. org/10.1093/hwj/9.1.5>

Peeters, Jeroen and Meg Stuart, eds, Are We Here Yet (Dijon: Les presses du réel, 2010)

Rancière, Jacques, The Emancipated Spectator, trans. by Gregory Elliott (London: Verso, 2009) Wijers, Gaby, Lara Garcia Diaz and Christian Sancto, eds, UNFOLD: Mediation by Reinterpretation - Annual Project Review Report, March 2016-March 2017 (Amsterdam: LIMA, 2017) <http://www.li-ma.nl/lima/sites/default/files/Unfold_verslag_excl. pdf> [accessed 12 March 2021] 